\title{
Hope: the human dimension of the cure
}

\section{G. Bordin}

\section{Niccolò Cannicci (1846-1906). Girotondo,1877 Oil on canvas}

Published online: 14 August 2009

(c) Springer-Verlag 2009

The pleasure of the three dancing girls enlivens a rural scene, which otherwise is circumscribed by a still and barren landscape, which only seems to rest in silence. A young shepherd looks on and applauds with amusement. The reason for this cheerfulness, almost brimming over into joy, is the awareness that soon all will be in flower. A sign can be seen in the sky, where the flight of a swallow announces the coming spring. It is a small but unambiguous sign which instils the wait with hope, because it is founded on the certainty of events which are unfolding now, and is more than a simple promise, as it contains the bud of new life.

The dynamics which Niccolò Cannicci (a "Macchiaiolo" painter) depicts in this canvas is the

\section{G. Bordin, Ospedale Piccole Figlie Parma, Italy} e-mail: giorgio.bordin@fastweb.it dynamics of every hope, which becomes sensible only when based on a here and now filled with promise. The desire of man even during a disease is the desire for a meaning for which life is worth living. If the physiological cure is the most immediate manifestation of this need, it is also true that the physiological cure alone is not enough, because man, although unconsciously, asks for more. He asks for something which can be reliable even within the limitations which the disease imposes upon him.

A healing relationship cannot truly be achieved without introducing this dimension into professional activity, a dimension resonating with the certainty of a positive outcome that no disease, by itself, can deny. This is the great responsibility of every healthcare worker: to carry this assurance in every action. No special skill is required to achieve this. It does, however, require great, infinite humanity.

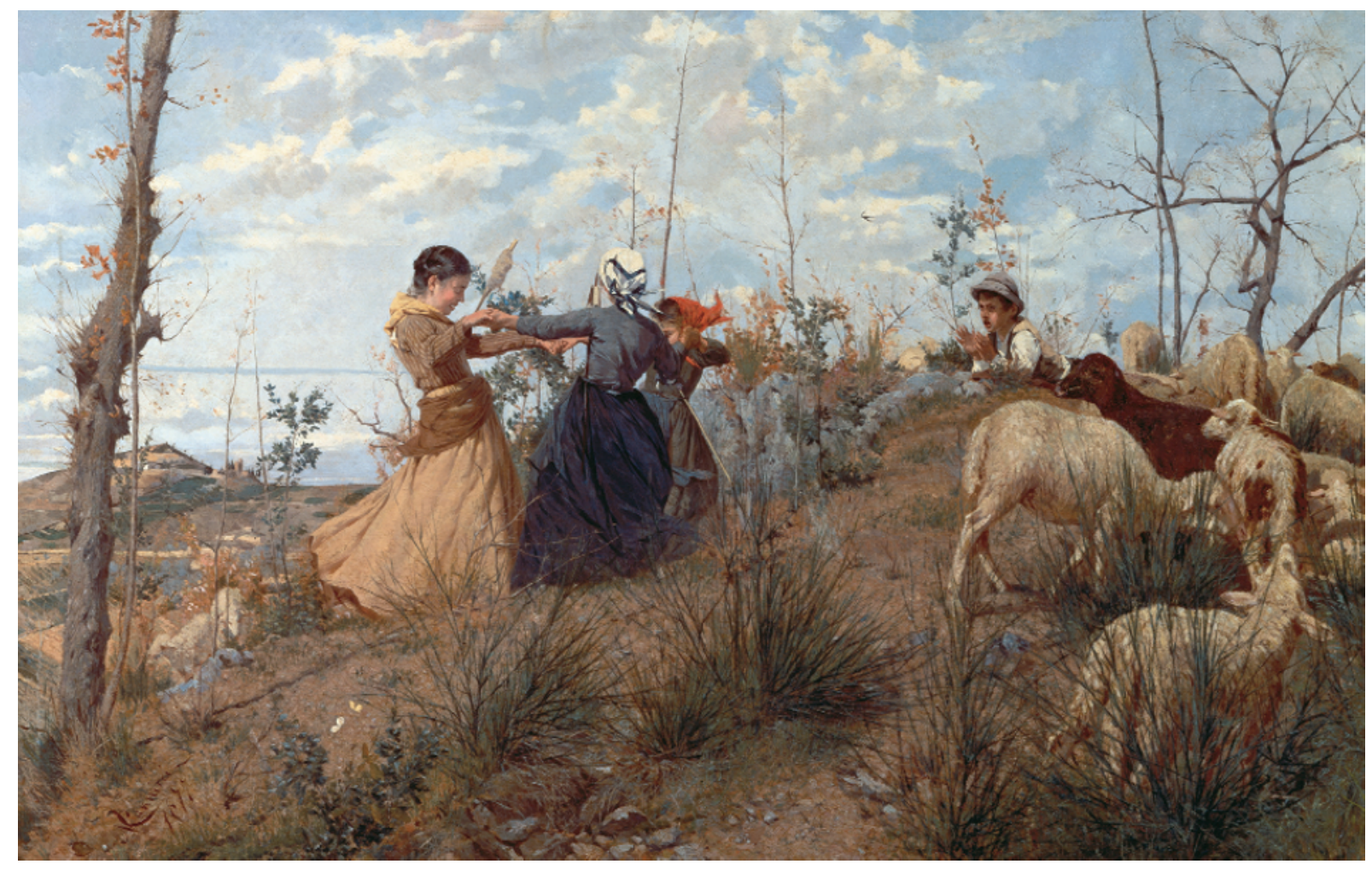

